Final version for C\&C June 2011

\title{
Laws and Tendencies in Marxist Political Economy1
}

\section{Steve Fleetwood}

University of the West of England, UK

\begin{abstract}
Whilst terms like 'law of the tendency', 'tendency law' and 'tendential law' appear in Marxist political economy, their meaning is unclear. This paper identifies the main conceptions of laws and tendencies buried in these terms and disambiguates them. Part one differentiates three conceptions of law: (i) event regularity; (ii) event regularity/tendency and (iii) tendency. Part two focuses on (ii) identifying five interpretations: tendency as a trend, cyclical variation, stochastically specified law, counterfactual event and a deliberately imprecise and under-elaborated concept. Part three introduces a sixth interpretation: tendency as the (transfactual) way of acting of a thing with properties. Part four explains why this conception of (genuine) tendency is impossible to mathematise.
\end{abstract}

\section{Key words}

Tendency, law, regularity law, tendential law, ontology, aetiology, critical realism

\section{Introduction}

It is well known that Marx conceives of laws in terms of tendencies. In discussing the tendency for profit rates to equalise, for example, he suggests that this equalisation be 'viewed as a tendency like all other economic laws' (Marx, 1984:175, passim, emphasis added). This conception has permeated Marxist political economy ever since, cropping up in discussions of inter alia the tendency of profits, wages, prices and intensification of labour to equalise; to create a reserve army of labour; towards centralisation and concentration of capital; of the productive forces to develop; to create a world market; and of the rate of profit to decline. Furthermore, there are many other tendencies that Marxist political economists are interested in, such as the tendency for men to be paid more than women and white people to be paid more than black people; the tendencies surrounding employment and unemployment; the tendencies toward economic crisis and so on. For anyone interested in Marxist political economy, tendencies are important.

Unfortunately, the terms 'tendency' and 'law' are ambiguous, and combining them in phrases like 'law of the tendential fall ', 'law of the tendency', 'tendency law' and 'tendential law' (I will use the latter term to refer to all such variants) merely compounds the problem. ${ }^{2}$ In the phrase, 'law of the tendential fall in the rate of profit', for example, it is not entirely clear whether the term 'tendential' is modifying the law or the fall; not entirely clear if the law or 
the fall is tendential. ${ }^{3}$ I will return to this later, but for now, it is worth noting that I am not the only one to have noticed ambiguity. For example, after mentioning Marx's claim to have discovered certain laws (i.e. tendencies) McBride adds: 'to be candid, the failure to say very much about the meaning of the term 'law' as he uses it is one of the most gaping lacunae in Marx's all too brief discussions of methodology' (MacBride 1997: 59). Further ambiguities will emerge as the paper unfolds.

Does ambiguity matter? I think so, for (at least) four reasons. First, conceptual clarity is its own reward. Second, ambiguity hides the 'infiltration' of Marxist political economy by empiricist and positivist notions which are anathema to Marxism's basic philosophical tenets. Third, ambiguous terminology of 'tendential law' and variants hides the fact that, of the six conceptions of tendency on offer, five of them turn out not to be (genuine) concepts of tendency at all. Finally, the only conception of tendency that is (genuine) is impossible to mathematise but ambiguity hides this. If disambiguation is necessary, how should we go about doing it?

I resist the temptation to 'go back to Marx', quite simply because he has several different conceptions of tendencies. Rather than trawl through Marx's work to show evidence of this, it is more efficient to make use of the excellent legwork already done by Reuten (1997, 2003, see also 1991). In his extensive, and extremely careful readings of Marx's key writings on the tendency of the rate of profit to decline, Reuten identifies several different conceptions of tendencies. Furthermore, some work has been done since Marx's day, specifically on laws and tendencies and this should not be ignored. The work I have in mind has been done, primarily, by critical realists following the insights of

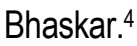

The objectives of this paper, then, are to use insights from critical realism to identify various conceptions of laws and tendencies, reflect upon their ontological and aetiological presuppositions and try to disambiguate these conceptions. The paper opens by differentiating three ways in which law can be conceived: law as event regularity; law as event regularity/tendency; and law as tendency. Part two turns attention to the second of these conceptions and identifies five interpretations: tendency as trend, cyclical variation, stochastically specified law, counterfactual event, and as a deliberately imprecise and under-elaborated concept. Whilst there are differences between these interpretations, they are actually variations on a theme and share important ontological and aetiological presuppositions. Clarification demands that their nuances be fully elaborated, hence the need to work carefully through them. When this is done, we will see that law as event regularity/tendency turns out not to be a (genuine) conception of tendency at all but the conception of regularity law disguised by the ambiguous terminology of 'tendential law' and variants. This gives the misleading impression that the conception of regularity 'law' is altered by the addition of 'tendency' when in fact the latter adds nothing to the former. Moreover, like the conception of regularity law, the conception of law as event regularity/tendency presupposes an atomist and empirical realist ontology, an aetiology based on the (Humean) event regularity view of causation and closed systems. Part three introduces a sixth interpretation, namely, tendency 
as the (transfactual) way of acting of a thing with properties with alternative ontological and aetiological presuppositions. This turns out to be a (genuine) conception of tendency. Part four explains why this sixth conception is impossible to mathematise for ontological and aetiological reasons. .

The following table shows, at a glance, the various combinations of law and tendency that will be elaborated upon as the paper unfolds.

\begin{tabular}{|l|l|l|l|l|}
\hline \multicolumn{2}{|c|}{ Six interpretations of tendency } & \multicolumn{1}{c|}{$\begin{array}{c}\text { Law as event } \\
\text { regularity }\end{array}$} & $\begin{array}{c}\text { Law as event } \\
\text { regularity/tendency }\end{array}$ & \multicolumn{1}{c|}{$\begin{array}{c}\text { Law as } \\
\text { tendency }\end{array}$} \\
\hline i & Trend & Yes & yes & no \\
\hline ii & Cyclical variation & Yes & yes & no \\
\hline ii & Stochastically specified law & yes & yes & no \\
\hline iv & Counterfactual event & yes & yes & no \\
\hline v & Imprecise/under-elaborated conception & yes & yes & no \\
\hline vi & $\begin{array}{l}\text { As the (transfactual) way of acting of a thing } \\
\text { with properties }\end{array}$ & no & no & yes \\
\hline
\end{tabular}

(Figure 1. Interpretations and conceptions of law and tendency at a glance)

Before we get underway, allow me to make two points. First, whilst I draw upon ideas on tendencies first floated by Lawson (1995) and to a lesser extent Hausman (1992: 128) my arguments extend well beyond their ideas and give the paper its originality. No-one has identified six interpretations of the term 'tendency'; no-one has argued that five of them are variations on a theme; no-one has suggested that law as regularity/tendency is actually law as regularity in disguise; few have offered meta-theoretical reflections on tendencies; and although a few Marxist political economists have toyed with the idea of tendency as powers, no-one has tried to connect Marxist and critical realist conceptions of tendency. ${ }^{5}$ Indeed, almost nothing has been written by Marxist political economists on the nature of tendencies in the last few decades. Second, amongst the examples I use is that of the tendency of the rate of profit to fall. I use this as a vehicle for elaboration, and make no attempt to comment on the empirics, or theories, of this tendency.

\section{Terminology relating to law and tendency}

It is virtually impossible to overstate the impact that the David Hume's ideas on causation have had, and continue to have, on our (mis)understanding of law and tendency (Psillos 2002: 19). The notion of causation championed by Hume, and used (explicitly or implicitly) by many economists (including Marxist), is referred to as the regularity view of causation. This view has two extremely important components: events, and event regularities. 
i) Events are the raw material, the building-blocks for many (but not all) concepts of law: they are the things, the episodes that happen and about which data is collected - e.g. the introduction of machinery, a change in capital to labour ratio, a change in wage, profit or unemployment rates and so on. If these events are experienced or observed (or proxied) in terms of quantity or degree they become variables. Variables are quantified events.

ii) Event regularities are the basis for all those (Humean) conceptions where causality is understood as nothing more than a constant conjunction of events, or event regularity. ${ }^{6}$ It is precisely the regularity in the flux of events that is, many beleive, the source of causality: where event regularities exist, they believe that a causal relation exists.

Conceptions of causality are inextricably bound up with conceptions of law. It is only a small (and consistent) step from the regularity view of causation, to what Psillos refers to as the regularity view of law, whereby 'laws of nature are regularities' (Psillos 2002: 137). On this conception, 'law' is the name given to an event regularity of the generic kind, styled: 'whenever event $x$ occurs, it is regularly followed by event $y$ '. From this perspective, a law is an event regularity and a law is causal because of this regularity.

Philosophers of science have debated, and continue to debate, these views on causality and laws. Indeed, there are contemporary critics and defenders of updated versions of the regularity view, and even some prepared to abandon ideas of causality and law as regularity. But my concern is not with philosophers of science and their use of the term 'law' - they rarely mention the term 'tendency' anyway. My concern is with Marxist political economists, one of whom, I consider myself to be. For now, though, let us pause to clarify the three important conceptions of law that have just been alluded to, noting the important role played by events and event regularities.

a) Law as event regularity. This conception is rooted in the regularity view of causation and the regularity view of law.

b) Law as event regularity/tendency. This conception is also rooted in the regularity view of causation, but this is not obvious because the term 'tendency' appears to modify the term 'law', giving the appearance that (a) and (b) are different.

c) Law as (genuine) tendency. This conception is most definitely not rooted in events, event regularities, or the regularity view of causation, but in the concept of causal power. 
One writer who is aware of the distinction I am trying to establish between law as regularity and law as tendency, even if only to reject it, is Ruben, who claims to be: 'genuinely worried that the tendency v. empirical regularity debate, if pushed hard enough, might well collapse into little more than a quibble about the use of the term "law"' (Ruben 1979b: 207. See also Ruben1979a and Gibson 1982). Whilst I disagree with Ruben on the grounds that there is far more at stake than a 'quibble', he draws our attention to the fact that the term 'law' can be used in several ways. It is sensible to reflect on this for a few moments to clarify a few misunderstandings, so that we can avoid being distracted by them later.

Some believe that all laws are about event regularities - as in (a) above. Others believe that because event regularities rarely, if ever, occur in the social world, then the social world is characterised by tendencies not regularities and not, therefore, laws. If laws are about event regularities, and tendencies are not, then laws and tendencies are different kinds of thing. Now some of this is right, and some wrong. It is wrong to say that all laws are about event regularities: some versions of law are about event regularities - and because of this henceforth I will differentiate between laws and regularity laws. It is right to say that tendencies are not about event regularities. But, unfortunately, conception (b) above, confuses tendencies with event regularities and, therefore, with regularity laws. It is right to say that regularity laws and tendencies are different kinds of thing, but wrong to say that laws and tendencies are different kinds of thing. Tendencies as in (c) are laws, but here laws are not regularity laws. It is right, therefore, to refer to 'law as tendency'. The phrase '(genuine) tendency' is used to differentiate between (genuine) tendency and non-(genuine) tendency whereby the term 'tendency' is confused with event regularities and regularity laws.

\section{Law as event regularity/tendency: five common interpretations}

This section focuses on the second of the conceptions just noted, namely, law as event regularity/tendency, because this is the conception of 'tendency' most often associated with 'tendential law' and variants. It identifies five slightly different interpretations that, nevertheless, share important ontological and aetiological presuppositions.

\section{i) Tendency as a trend}

It might be said that the rate of profit will tend to fall over time. For example, Tsaliki \& Tsoulfidis (1994: 46) set out to empirically investigate a 'secularly falling rate of profit'. For them, 'empirical research confirms that there is a long-run downward tendency in the rate of profit for the advanced capitalist countries, which started in the late 1960s or early 1970s' (ibid: 49). Moseley (1991: 152) concludes that 'the trends of the Marxian variables for the post-war long-wave period of expansion were largely consistent with Marx's hypothesis that the rate of profit would tend to decline due to technological change'. This seems to be what Fine \& Harris (1981: 64) refer to as a 'downward trend (or regression line)' or an 'empirical tendency'. Tendency, then, is conceived of as an empirically observed pattern in the flux of events, in this case the pattern indicates a decline in the rate over time. 


\section{ii) Tendency as a cyclical variation}

Closely related to the last interpretation is the idea that the rate of profit will tend to cycle. ${ }^{7}$ This might be what Moseley (1991:1) has in mind with the concepts: 'medium-run long waves, and short-run cycles'. Some have conceived of the tendency of the rate of profit to decline in terms of Kondratieff-type waves. Reuten cites Marx (1997: 168 , emphasis original) suggesting that tendency as cycle is probably Marx's interpretation. 'The stagnation in production that has intervened prepares the ground...for a later expansion of production. And so we go round the whole circle again'. The italicised phrase gives the impression of some measure of the rate of profit being observed to fluctuate over time. Once again, tendency is conceived of as an empirically observed pattern in the flux of events, in this case, the pattern indicates cyclical movements in rates over time.

\section{iii) Tendency as a causal law, probabilistically or stochastically specified}

It might be said that the rate of profit will tend to fall as the organic composition of capital rises. The term 'tend' is used here to give the analysis in a probabilistic or stochastic expression. ${ }^{8}$ And this in turn is used in recognition of the fact that factors like increases in the productivity of labour, or indeed more concrete factors such as increasing intensity of exploitation, depression of wages, government policy, and so on could also have offsetting effects - indeed, these offsetting entities are often referred to as 'counteracting influences' (Fine \& Harris 1981: 62). Expressed stochastically, the strict condition that every single instance of a rise in the organic composition of capital is constantly conjoined with every single instance of a fall in the rate of profit (that forms the basis of the regularity view of law) can be abandoned for a 'weaker' version, whereby most instances of rises in the organic composition of capital are constantly conjoined with most instances of a fall in the rate of profit. More accurately, the mean value of variable $x$ (measuring the organic composition of capital) is constantly conjoined with the mean value of variable $y$ (measuring the rate of profit). More generally, the mean value of variables $x_{1}, x_{2} \ldots x_{n}$ are constantly conjoined with the mean value of variable $y$. This, of course, means that some observed values of $x_{1}$, $x_{2} \ldots x_{n}$ will not be constantly conjoined with all the observed values of $y$. Note well that this notion of tendency is still built upon events and event regularity; the event regularity is simply now expressed stochastically. Yet again tendency is conceived of as an empirically observed pattern in the flux of events, in this case, the pattern is simply expressed stochastically. ${ }^{9}$

\section{iv) Tendency as a counterfactual event}

Counterfactual reasoning (not to be confused with transfactual reasoning which I will elaborate upon in section three) is often used in economics. ${ }^{10}$ Counterfactual conditional statements, or counterfactual conditionals for short, state, or enquire about what has, or what might, have occurred had conditions been different. They are counter-factual statements in the sense of being counter, or contrary to, the empirical fact. Thus we might say: 'if this match were struck in appropriate conditions, it would ignite'. Statements of this kind are not only counterfactual, they are also 
conditional. A conditional clause, or, if-clause, is added to the main clause (set of words containing a verb) which is why they are referred to as 'conditional' statements. Adding an if-clause to the base form of the verb gives sentences like: 'the rate of profit would fall if the organic composition of capital productivity rises', where 'would' is the if-clause and 'fall' is the base verb. The type of conditional statement we are interested in here, uses the subjunctive mood of verbs, to express what is imagined or possible - as opposed to the indicative mood expressing statements of fact. Typical if-clauses are: 'will', 'can', 'may', 'might', 'would' or 'could'. A typical counterfactual conditional used in economic theory then, does not express something that has happened (i.e. a fact), but rather something that has not happened (i.e. contrary to the fact), but might happen, if conditions had been different, or if appropriate conditions come about in future.

When counterfactual conditionals are used in economic theory they almost always come as a package involving statements about: (i) the antecedent (e.g. 'the organic composition of capital rises'); (ii) the consequent (e.g. 'the rate of profit would fall'); and (iii) the wider conditions (e.g. assumptions and axioms). Assumptions can be allencapsulating but non-specific, like the ceteris paribus clause; or specific, like the assumptions of 'management processes remain constant'. An axiom might be that 'agents are rational'. Thus we might say:

a) 'The rate of profit would fall if the organic composition of capital rises, assuming management practices remain constant, ceteris paribus'.

Notice that statements about wider conditions complicate matters. The consequent ('the rate of profit would fall') is now not only dependent upon the antecedent ('the organic composition of capital rises') but also on the assumption that management processes remain constant and on the ceteris paribus clause. Indeed, because the ceteris paribus clause is non-specific, we do not really know what it applies to. This makes it difficult to untangle the antecedent from the conditions, that is, from the axioms, assumptions and ceteris paribus clause. It is no longer clear exactly what the antecedent is - or the antecedents are. But matters are even more complicated because there are many more conditions that must also remain constant if the rate of profit is to fall following a rise in the organic composition of capital. Thus, instead of (a) above, it is more accurate to write:

b) 'The rate of profit would fall if the organic composition of capital rises, not only assuming management practices remain constant, but also assuming that marketing practices, industrial relations systems, macroeconomic conditions, etc, etc, all remain constant, ceteris paribus.

Whilst it might be possible to extend the list of assumptions, there will almost always be some that remain unstated. It is difficult to refer to unstated assumptions as 'assumptions' because assumptions are stated. I refer to them instead as 'presumptions'. For reasons that will become clear in a moment, critical realists use the term 'closure conditions' 
as a generic term to encapsulate axioms, assumptions, presumptions and the ceteris paribus clause used with counterfactual conditional statements.

A counterfactual conditional statement to the effect that 'the rate of profit would fall if the organic composition of capital rises', given closure conditions, presupposes a (potential) event regularity - i.e. 'if the organic composition were to rise (event $\mathrm{x}$ ), the rate of profit would fall (event $\mathrm{y})$ ' - i.e. 'whenever event $\mathrm{x}$, then event $\mathrm{y}$ '. And a system characterised by event regularity (potential or otherwise) is what critical realists refer to as an open system - by extension, a closed system is one characterised by a lack of event regularity. Counterfactual conditionals, then, presuppose closed systems. But, as critical realists (and some fellow travellers) argue, socio-economic systems are, typically, open not closed systems. Economists deal with open systems, typically, by closing them, but only in theory of course. This is why an extensive set of closure conditions (i.e. axioms, assumptions, presumptions and a ceteris paribus clause) always accompany counterfactual conditional statements.

Now we come to the crux of counterfactuals. ${ }^{11}$ With counterfactual conditionals there is no necessity that the antecedent be instantiated. Indeed this is exactly why counterfactual conditionals use the subjunctive mood of verbs; they express what is possible. Counterfactual conditionals do not state what is actually occurring here and now; they state that something might occur ceteris paribus. They are not statements of fact, they are statements contrary (counter) to fact. In this example, there is no necessity that the antecedent ('the organic composition of capital rises') is instantiated. Counterfactual conditionals simply say if the organic composition of capital were to rise, then the rate of profit would fall, but remain silent on the status of the 'if'. Indeed, the 'if' may never occur, but even if it did not, this would not invalidate the counterfactual conditional.

What, then, is tendential about counterfactual conditionals? The term 'tendency' is used instead of regularity 'law' because: (a) the antecedent may not be instantiated; (b) the consequent might not follow from the antecedent; (c) the antecedent cannot be untangled from the closure conditions; and (d) the closure conditions are unlikely to come about. The term 'tendency' itself is a counterfactual event. In this case, the counterfactual conditional is the fall in the rate of profit.

There is, however, one important thing to add here that differentiates this interpretation from the previous three. Whilst the tendency refers to the counterfactual event (i.e. the fall in the rate of profit) this counterfactual event has not been observed. There is an important presumption at work here. The presumption comes in the form of a reasonable expectation that the events in question would come about (and hence would be observed) if the extensive closure conditions were realised. If this is not presumed, however, then the exercise is open to the charge of irrelevance. If there is no reasonable expectation that the extensive closure conditions would be realised, then 
claims about the events in question would become irrelevant. In this case, tendency is conceived of not as an empirically observed, but as a potentially observable pattern in the flux of events.

Counterfactual conditionals are used by 'neo-classical Marxists' such as Okishians, Sraffian inspired neo-Ricardians such as Steedman (See Johnson, Gramm \& Hoas 1991) and, arguably, any Marxists engaged in mathematical modelling.12 Michl's (1994) paper entitled 'Three Models of the Falling Rate of Profit' is a paradigm case.

\section{v) Tendency as a deliberately imprecise and under-elaborated conception}

This fifth interpretation is far more circumspect than the previous four, but I think it is still worthy of inclusion on the grounds that it is often used in conversation, discussion, or even literature. It is used in a deliberately non-technical way to refer to some kind of imprecise and under-elaborated pattern in the flux of events. It does not necessarily imply strict event regularity, or a stochastic regularity (although it could) but neither does it imply complete event irregularity either. This kind of thing is sometimes referred to with terms like 'stylised facts' or 'demi-regularities'. ${ }^{13}$ The deliberate imprecision and under-elaboration is useful because it allows those who use it to make (theoretical or empirical) headway without being distracted by having to explain the meaning of the term. In this case, once again, tendency is conceived of as an empirically observed pattern in the flux of events.

\section{Pause for reflection ${ }^{14}$}

Let us reflect upon the last five interpretations of law as event regularity/tendency.

i) The raw material out of which law as event regularity/tendency is constructed is the event, or events.

ii) Events are isolated, unique, unconnected, punctiform, or atomistic episodes. They must be atomistic, since any connection between them would be impervious to observation, and the nature of the connections would require prior explanation, thereby undermining the centrality of the observable. The ontology is one of atomistic events.

iii) These events are empirically observed or potentially observable, making the ontology empirical realist - not to be confused with critical realist. Reference to a law as event regularity/tendency is, in part, reference to observable, or potentially observable, events.

iv) Event regularities are (allegedly) the basis of knowledge. Where there exist patterns in the flux of events, in the form of event regularities, there is a basis for making knowledge claims - i.e. we can test theories by setting them up as predictions of the kind: event $y$ is predicted to regularly (not just occasionally) follow 
event $x$. Where the flux of events does not display a pattern in the form of event regularities, there exists no basis for making knowledge claims - i.e. we have chaos and accident.

v) Event regularities are the basis for the regularity view of causation. Reference to a law as event regularity/tendency is, in part, reference to event regularities, making the aetiology regularity-based.

vi) Summing the last five points, law as event regularity/tendency presupposes an atomist and empirical realist ontology, an aetiology based on the (Humean) event regularity view of causation and, by extension, closed systems.

vii) Despite the fact that the conception of law as event regularity/tendency contains the term 'tendency', the term 'tendency' is redundant: it adds nothing to the term 'law'; it is window dressing. The conception of law as event regularity is all that is needed, provided it is expressed stochastically. This is disguised by the ambiguous terminology of 'tendential law' and variants, which give the misleading impression that the conception of regularity law is somehow altered by grafting on the term 'tendency'.

This final point is important and requires a little more elaboration, so allow me to proceed in two steps. First I will compare the orthodox economic treatment of what might be called the tendential law of labour demand to the tendential law of falling rate of profit. Second I will compare Ohms Law to a hypothetical tendential law of the falling rate of profit.

\section{A 'tendential' law of labour demand}

Many Marxist political economists doubt the existence of the regularity law of labour demand - i.e. the existence of a well-behaved and correctly signed labour demand function. The existence of offsetting factors means that, following a rise in wage rates, sometimes the demand for labour falls, sometimes it does not change and sometimes it rises. Some would refer to this regularity law as a tendency or perhaps even the tendential law of labour demand - or variants. Indeed this is precisely what a leading orthodox labour economist does, writing:

In the case of labour demand, this means that the imposed increases in labour costs reduce labour demand. Changes in relative wages shift relative worker-hours in the opposite direction, and relative wage changes in the components of labour costs alter the mix of employment and hours in the opposite direction. The changes might not be immediate. Indeed, there may not be any response if decisions about employment are lumpy... How large the responses is an empirical question...But that there is a tendency for firms to reduce employment when wages increase and 
shift relative employment towards workers who become relatively less expensive is undeniable (Hamermesh 1993: 58, emphasis added). ${ }^{15}$

What Hamermesh means by a 'tendency for firms to reduce employment when wages increase', however, is actually no more than a '(stochastically specified) regularity law for firms to reduce employment when wages increase'. There is nothing to be gained by substituting the term 'tendency' for regularity 'law', or from grafting the term 'tendency' to the term 'law' as in 'tendential law' and variants. The term 'tendency' is redundant. In short, Hamermesh is not dealing with a tendency at all, but with a regularity law: the regularity law of labour demand specified stochastically.

The same arguments can be made in the case of the declining rate of profit - stochastically specified. Most Marxist political economists doubt the existence of the regularity law of the declining rate of profit - which is, of course, precisely why they turn to the terminology of 'tendential law'. The existence of offsetting factors means that following a rise in the organic composition of capital, sometimes the rate of profit declines, sometimes it does not change and sometimes it rises. What is meant by a 'tendency for the rate of profit to fall', is actually no more than a (stochastically specified) regularity law for the rate of profit to decline when the organic composition of capital rises. There is, however, nothing to be gained by substituting the term 'tendency' for regularity 'law', or from adding the term 'tendency' to the term 'law'. Once again, the term 'tendency' is redundant. In short, we are not dealing with a tendency, but with a regularity law: the regularity law of the falling rate of profit.

\section{Ohm's law}

Ohms Law is a paradigm case of what is (mis)understood as law as event regularity. ${ }^{16}$ In this section I will show that this (mis)conception presupposes an empirical realist ontology of observed events; the regularity view of causation; the regularity view of law; and closed systems. Then I will take a model of profit rates from Marxist political economy and show that it rests on exactly the same four presuppositions. Furthermore, I will show that it is impossible to insert the term 'tendency' into this model and refer to it as something like 'a tendential law of rate of profit to decline', demonstrating, once again, that the term 'tendency' is redundant.

Ohm's Law states: The direct current flowing in a conductor is directly proportional to the potential difference (voltage) between its ends. It is usually written:

1) $\quad V=I . R$

Where $V$ is the potential difference, the voltage, $I$ is the current, and $R$ is the resistance. 
It is straightforward to show that this (mis)conception presupposes: an empiricist ontology of observed events; the regularity view of causation; the regularity view of law; and closed systems. Ohms Law expresses event regularities between three variables such that a change in the magnitude of one variable is regularly conjoined with changes in the magnitude of one or the other variables. This can be expressed in several ways. We can write: 'whenever a change in I (an event) and $R$ (an event), then a change in $V$ (an event)'. We can express this more generally and write 'whenever events $x_{1}$ and $x_{2}$, then event $y$ '. We can also express this as: $V=f(l, R)$ or more generally $y=f\left(x_{1}\right.$ and $\left.x_{2}\right)$. Moreover, it is only in virtue of the fact that the magnitude of $V$ varies regularly, and not just occasionally, with changes in the magnitude of $I$ and $R$ that we have grounds for thinking that causality is present. On this understanding, causality is inextricably tied to event regularity: where there is event regularity, we are allowed to imply causality; where there is no regularity, we must deny causality. And where there is event regularity, there is a closed system. ${ }^{17}$ Many electronic systems do, of course, display event regularity and, thereby, approximate closed systems.

\section{A model from Marxist political economy}

Now let us consider the following Marxist model, from Laibman (1993:229):

(2) $\quad r^{*}=r+(U / C)$

Where:

$\begin{array}{ll}r^{*} & \text { denotes the 'Marxian' rate of profit } \\ r & \text { denotes the profit rate, } P / C \\ C & \text { denotes constant capital } \\ P & \text { denotes profit } \\ U & \text { denotes the wages of unproductive workers } \\ U / C & \text { denotes the ratio of unproductive flow to constant capital. }\end{array}$

Models like these are not usually accompanied by the term regularity 'law' in Marxist political economy, but by terms like 'tendential law' and variants. The important point, however, is that they make the same ontological and aetiological presuppositions as (misunderstood versions of) Ohm's Law. In this respect, model (2) is no different from (1). It is only by ambiguous use of terminology that we end up with the terms regularity 'law' and 'tendency' being used as if they were the same, or similar things, when they are not. To highlight the way this ambiguity disguises the problem, let us see what would happen if we tried to insert the term 'tendency' (by which I mean (genuine) tendency) into (2) and refer to it as something like 'a tendential law'. 18 We might write: 
(2a) $r^{*}$ tends to $=r+(U / C)$

At this point we would run into a series of conundrums and problems.

In (2a) the operator 'tends to equal' would, of course, be meaningless. ${ }^{19} r^{*}$ does not tend to equal $r+(U / C) . r$ does equal $r+(U / C)$. (2) is a precise expression and we know precisely what it means. It means $r^{*}$ varies positively with $r$ and $U$ and negatively with $C$. But (2a) is not a precise expression and we do not know precisely what it means. We do not know what it would mean to say: $r^{\star}$ tends to vary positively with $r$ and $U$ and negatively with $C$.

One way to deal with this conundrum is to give the term 'tend' a stochastic inflection. We might re-interpret equation (2) as 'the mean values of variables $r, U$ and $C$ are constantly conjoined with the mean values of variable $r^{* \prime}$, and re-state it stochastically as:

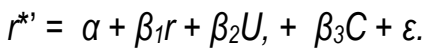

This does not, however, require the addition of the term 'tendency'. Indeed it can be dealt with via Hempel's Inductive Statistical (IS) model - i.e. the Deductive Nomological (D-N) model augmented to take account of stochastic generalisations. In this case, a strict or deterministic regularity law is merely re-stated as a stochastic regularity law.

What, we might ask, would this (tendential) function actually look like? If it turned out to be a straightforward function (linear or non-linear, simple of complicated) mapping one set of values onto another set, then once again the term 'tendency' would be redundant; we would have a straightforward (stochastic or inductive) regularity law, relating variables $r^{*}, r, U$ and $C$.

This has two important lessons for the (attempted) mathematisation of (genuine) tendencies. First, inserting the operator, 'tends to equal' into a mathematical function results in nonsense. Second, giving the term 'tend' a stochastic inflection allows us to use mathematics - i.e. in the case of (3), a straightforward econometric specification. But in this case we would not have not mathematised a (genuine) tendency, merely a stochastic regularity law.

\section{Summary}

Law as event regularity/tendency presupposes an atomist and empirical realist ontology, an aetiology based on the (Humean) event regularity view of causation and closed systems. Because these presuppositions are all rooted in 
empiricist and positivist philosophical traditions that Marxists have fought against for over a century, we should be wary of letting them back in 'by the backdoor'. Moreover, when unpacked, the conception of law as event regularity/tendency turns out not to be a (genuine) conception of tendency at all: it is really the conception of regularity law disguised by the ambiguous terminology of 'tendential law' and variants. The conception of law as event regularity/tendency is misconceived and should be abandoned. I advocate its replacement with the conception of tendency is the (transfactual) way of acting of a thing (or things) with properties.

\section{Interpretation (iv): tendency as the (transfactual) way of acting of things with properties ${ }^{20}$}

It might be said that the rate of profit tends to fall, because the tendency is the (transfactual) way of acting of a thing (or things) with properties (Fleetwood 2010). The term 'tendency' is used to refer, metaphorically speaking, to something that powers, forces, drives, propels, pushes, presses, shoves, thrusts, exerts pressure and so on. Notice that, in complete contrast to the other five interpretations the tendency does not refer to an empirically observed (or observable) pattern in the flux of events. Indeed, the tendency refers to some, as yet unspecified, thing with properties that may or may not cause empirically observed (or observable) events. There are two key points to note here, and they turn on a comment made in part one vis-a-vis events and event regularities. First, association of the tendency with events and their regularities that underpins the previous five interpretations, is broken. A tendency can be in play and yet not manifest itself at the level of empirical events due to the influence of counteracting tendencies. Second, the association of the tendency with causality as event regularity that also underpins the previous five interpretations is broken. A tendency can be (causally) in play and yet not manifest itself in an event regularity. Here we see a complete break with Humean notions of causality as event regularity noted above. On this sixth interpretation, a tendency is causal, but causality is more than event regularity. Fine \& Harris (1981: 64) might well have something like this in mind when they refer to 'abstract tendency' which, they add, 'does have a connection with observable entities even though it does not involve simple predictions of trends (ibid: 71). It is also likely to be what Reuten has in mind when he writes: 'tendencies are about 'forces' and when he links 'tendency' to some 'power entity' (Reuten 1997: 151).

On this interpretation a tendency is transfactual, but not counterfactual as in interpretation (iv) above. The difference between transfactual and counterfactual conditionals is subtle, and often difficult to grasp, but because it is important we cannot ignore it. Counterfactual conditionals state what might have occurred, had conditions been different and hence are counter, or contrary, to the empirical fact. Transfactual conditionals state what is actually occurring here and now. They do not, therefore, require a ceteris paribus condition. They do not say $\Omega$ would occur ceteris paribus; they say $\Omega$ is occurring here and now, but because the consequent may be unrealised, the consequent may be nonempirical, or against the empirical fact. Indeed, what is actually occurring here and now might appear to be nothing at all. As I hold my pen, gravity is acting transfactually on it, acting non-empirically, or against (trans) the empirical fact of the pen falling due to the effects of gravity. It appears, of course, that nothing is going on here; but this 
appearance is misleading. A lot is going on. Gravity is acting, as are the muscles in my hand and arm. The fact that the result (the consequent) is stasis is beside the point - although it gives empiricists a serious problem. Here we come to the crux of the distinction between transfactuals and counterfactuals. As we saw on p?, with counterfactuals, the antecedents need not be instantiated; but with transfactuals the consequents need not be realised. Transfactual conditionals 'are not second best kinds of empirical generalisations. They are not empirical statements at alp (Bhaskar 1978: 102 emphasis added). I will make use of transfactuality again in a few moments.

This sixth interpretation is radically different from the previous five. To continue with the metaphor used above, we might say that on this interpretation, the tendency is 'attached' to the thing with properties. The tendency does not refer to the outcomes of something, like regular patterns in the flux of events. To put matters starkly, a tendency could be in operation even if no events were occurring and/or being (potentially) observed, because the tendency might be neutralised by (countervailing) tendencies coming from some other thing(s). Put another way, the rate of profit could be tending to fall, even if the empirically observed events indicated that the rate of profit was rising.

The differences between the first five and the sixth interpretation can be illustrated by making use of the oft-used critical realist diagram illustrating a 'layered' ontology, augmented to include the (i) law as event regularity and (ii) law as tendency in the right hand column.

\begin{tabular}{|c|c|c|}
\hline Domain & Entity & Notion of law or tendency \\
\hline Empirical & Experiences \& observations & \multirow{2}{*}{$\begin{array}{c}\text { Law as event regularity/tendency } \\
\text { where the tendency is a pattern in } \\
\text { the flux of events }\end{array}$} \\
\hline Actual & Events \& actions & \\
\hline 'Deep’ & $\begin{array}{l}\text { Structures, institutions, mechanisms, } \\
\text { rules, conventions, resources etc }\end{array}$ & Law as tendency \\
\hline
\end{tabular}

(Figure 3. A 'layered' ontology with tendencies)

The diagram makes it easier to gasp the point that law as event regularity/tendency is an empirical realist conception. The tendency is located in the domains of the empirical and the actual, 'attached' to experiences and/or events, and these (fused) levels are the only ones that constitute the world of the empirical realist. This is in complete contrast to tendency as the way of acting of a thing with properties. Here the tendency is located in the domain of the 'deep', and 'attached' to structures, institutions, mechanisms, rules, conventions, resources etc. 
Reuten is one of the few Marxists to have spotted this conception of tendency and recognises something of the distinction I am trying to maintain between tendency as outcome (qua events) and tendency as the way of acting of an entity or thing with properties.

The least one can say is that tendencies are about 'forces' and (their) 'expressions,' or about 'powers' and (their) 'outcomes'...The main divergent conceptions are either to see powers as tendentially in operation (thus to link 'tendency' to some power entity) or to see the outcome as a tendential occurrence (Reuten 1997: 151).

In order to fully appreciate the sophistication of this interpretation of tendency, we need to 'take a step back' and reflect upon the entity or thing that is said to have a tendency. To do this, I draw upon two previous papers. In Fleetwood (2010) my concern is with powers not tendencies. Fleetwood (2011) goes one step further and argues that power and tendency refer to the same phenomenon. I will not rehearse this argument here, but simply assert the idea. In what follows, I modify my 2010 comments in the light of my 2011 comments. The odd thing is that nothing of substance changes by substituting the term 'tendency' for 'power'.

- Things include inter alia objects, natural objects, particulars, powerful particulars and substances. Things can be physical (hearts, rocks, oceans); artefactual (companies, computers, dominos); social (organisations and relations such as class) or ideal (discourses, beliefs).

- Properties include inter alia attributes, constituents, features and qualities - of things. Properties can be parts or components, such as the components that constitute a capitalist firm.

- Tendencies include inter alia 'powers', 'affordances', 'abilities', 'capacities', 'dispositions', 'forces', 'liabilities', 'potentialities', 'potencies', 'predilections', 'processes', 'propensities'.

Things, properties and tendencies all emerge simultaneously to form a unity. The moment a thing emerges from other things (with their own properties and tendencies) so too do its properties and tendencies. Things, properties and tendencies are emergent from, but irreducible to, other things, properties and tendencies. Things have properties, these properties instantiate transfactually acting tendencies, and this ensemble of things, properties and tendencies (may) cause events. It is worth pointing out that when critical realists refer to 'causal' or 'generative mechanisms', they are, in fact, referring to things with properties and tendencies. Consider two examples. 
- The moment a lump of ice breaks off a glacier and falls into the Arctic Ocean, a thing, an iceberg emerges. At the same moment, the icebergs' properties (e.g. being dense, white and with a temperature below freezing) emerge as do its tendencies (e.g. to float on water, to sink ocean liners).

- The moment a capitalist assembles an appropriate set of things (e.g. workers, plant, machinery, IT systems, semi-finished products, raw materials, socio-cultural or discursive management techniques and mechanisms for making and receiving payments), a thing, a capitalist company, emerges. At the same moment, the companies' properties (e.g. having workers, plant and machinery and using socio-cultural or discursive management techniques) emerge as do its tendencies (e.g. to produce commodities and generate profit). ${ }^{21}$

Most things, with their properties and tendencies are, typically, bundles of other things with their properties and tendencies which, in turn, are bundles of other things with their properties and tendencies and so on - note that the conception of emergence prevents this from being reductionist. This is just another, albeit more accurate, way of saying that causal mechanisms are, typically, bundles of other causal mechanisms which, in turn, are bundles of other causal mechanisms and so on. Most of the entities social scientists deal with, such as capitalist companies or even whole socio-economic systems, are actually bundles of things with their properties and tendencies, or bundles of causal mechanisms.

For a company to possess the tendency to generate profit it must, at a minimum, have assembled the appropriate quality and quantity of intrinsic things with their properties and tendencies, and must have coordinated them appropriately - I am abstracting from any extrinsic things with properties and tendencies for ease of exposition. Clearly, this involves thousands, if not millions of intrinsic components. A company that has assembled, and coordinated, the appropriate quality and quantity of workers, plant, machinery, IT systems, semi-finished products, raw materials, management techniques and mechanisms for making and receiving payments will, we assume, possess the tendency to extract profit. Note that if the company has this tendency, then these components cannot simply be a 'heap', but must be systematically arranged and coordinated - and one of the tasks of management is, of course, to try and ensure such systematicity.

Now, where do tendencies fit into this scenario? In the Dictionary of Critical Realism, Pinkstone \& Hartwig (2007: 459) advance what is, arguably, the commonly held view of a tendency. 'A tendency, in its primary meaning, is a causal power exercised or set in motion'. According to Bhaskar:

[W] hereas powers are potentials which may or may not be exercised, tendencies are potentialities which may be exercised or as it were 'in play' without being realized or manifest in any particular 
outcome.... [T]endencies are powers which may be exercised without being fulfilled or actualised...It is the idea of continuing activity as distinct from that of enduring power that the concept of tendency is designed to capture. In the concept of tendency, the concept of power is thus literally dynamised or set in motion (Bhaskar 1978: 50).

Let us explore this with the example of a capitalist company. The term 'tendency' refers to what the company can do; it can generate profit - although it does so transfactually. Thus, once the company has assembled, and coordinated, the appropriate quality and quantity of workers, plant, machinery, IT systems, semi-finished products, raw materials, management techniques and mechanisms for making and receiving payments, then it has the tendency to extract profit. But, because this tendency acts transfactually, it might not manifest itself in the extraction of profit - it might even manifest in a loss, but could still have a tendency to make a profit. If and when this tendency is put into action, exercised, set in motion, or whatever verb we choose, then the company has a tendency to extract profit. When we think of a tendency as the transfactual way of acting of a thing with properties, we 'attach', metaphorically speaking, the tendency to the thing with properties. A tendency, then, is the (transfactual) way of acting of things with properties.

\section{What is tendential: the law or the fall?}

At this juncture, we are able to return to a point noted in the introduction where I mentioned the phrase law of the tendential fall in the rate of profit' and noted that it is not entirely clear whether the term 'tendential' is modifying the law or the fall; not entirely clear if the law or the fall is tendential. Recall from part one the following three fold distinction that has been used throughout this paper:
a) Law as event regularity.
b) Law as event regularity/tendency.
c) Law as (genuine) tendency.

In (a) and (b) the conception of a 'fall' would refer to the (negatively signed) change in the magnitude of a variable that follows a change in another variable(s). Given that variables are quantified events, a change in the magnitude of a variable represents a change in events. A fall would, thereby, refer to a change in events. In the example, the fall in question refers to a (negatively signed) change in the amount of profit ( $r$ ) generated by a change in the amount of machinery (c); a change in the number of workers (v); and/or a change in the amount of surplus value (s). Let us reflect upon this using the three-fold distinction.

In (a) if a change in $c, v$ and/or $s$ is regularly conjoined to a fall in $r$, then we have a straightforward regularity law, where $r=f(c, v, s)$. 
In (b) if a change in $c, v$ and/or $s$ is 'related' to a fall in $r$, but the 'relation' is not one of regular conjunction, then we have the kind of scenario where the conception of law as event regularity/tendency is, typically, used. We might, for example, interpret this stochastically and write something like:

$$
r=\alpha+\beta_{1} c+\beta_{2} v+\beta_{3} s+\varepsilon
$$

We now have stochastic event regularity and stochastic regularity law.

In (a) the fall is a straightforward case of event regularity; the event regularity is the law; and the fall is the law the term 'tendential' is not used.

In (b) the fall is the stochastic event regularity; the event regularity is the stochastic law, or put differently, the event regularity is the stochastic tendency; and the fall is the stochastic law, or put differently, the fall is the stochastic tendency. The term 'tendential' could be modifying the regularity law because the difference between (a) and (b) is that in the latter the regularity law is expressed stochastically. Notice, however, that stochastic regularity law, stochastic tendency and stochastic fall are all different ways of referring to the same phenomenon, namely, a stochastic event regularity. Because of this, the term 'tendential' could be modifying the law or the fall. The confusion stems from the fact that the term 'tendency' in the conception of law as event regularity/tendency, is not a (genuine) tendency, but a regularity law disguised by the ambiguous terminology of 'tendential law' and stochastic expression.

In (c), matters are very different. Where a tendency is the (transfactual) way of acting of a thing with properties, there is no need for ambiguous phrases like the 'law of the tendential fall in the rate of profit'. We can simply refer to the 'tendency of the rate of profit to fall'. In this case, tendency is not confused with events or their regularities, stochastic or otherwise - recall that a tendency can be in play and yet not manifest itself at the level of empirical events. Neither is tendency confused with fall because a fall is an (empirical) change in events. The term 'tendential' does not, therefore, modify the fall. What is 'tendential', then, or what acts 'tendentially' is some thing with properties - such as an iceberg or a capitalist company. To refer to a tendency of the rate of profit to fall is to refer to the (transfactual) way of acting of capitalist companies competing with one another.

\section{A brief comment on tendencies and dialectics}

Before concluding, I want to say a little about tendencies and dialectics. Law as tendency, where tendency is the (transfactual) way of acting of things, is a dialectical concept. Law as tendency/regularity, built as it is upon a foundation of empirically (or potentially so) observed events, subsequently quantified and transformed into variables, is an ontologically atomist, empirical realist and non-dialectical conception. Marxist political economists (implicitly or 
explicitly) using these concepts should be very wary about drawing upon a philosophical tradition that is anathema to Marxism. Allow me to elaborate a little.

First, in the empirical realist conception, events are isolated, unique, unconnected, punctiform or atomistic episodes. But atoms are not dialectical entities. Lacking any connection to other atoms, they lack the kind of properties that would allow them to interpenetrate with their opposites - interpenetration is connection. Operating from a dialectical perspective, Brown et al (2002: 744) argue that critical realism's lack of systematic dialectics leaves it unable to capture the 'inner connection' of or between phenomena. Whilst their claim vis-a-vis critical realism may not be entirely true (as we will see in a moment) there is no question whatsoever that it is true of the empirical realist conception of events and, thereby, of law as event regularity/tendency: atoms cannot have an 'inner connection' within or between them.

Second, all an event, duly transformed into a variable, can do is increase or decrease its magnitude or change its sign. It cannot undergo a change in its nature or negate itself and become something else - indeed, if it does, then it violates one of its characteristics of being a variable (Fleetwood 2001a).22 The best we could do to try and 'squeeze' something that looks like a dialectical contradiction out of a law as regularity/tendency is to estimate a regression equation, note that one independent variable is positively signed, whilst another one is negatively signed. Attempts to pass this positive/negative scenario off as some kind of dialectical contradiction would be a case of spurious dialectics. Indeed, if this was a dialectical contradiction, then we would have to admit that tens of thousands of orthodox econometricians are unknowingly dialecticians!

Third, a tendency as the (transfactual) way of acting of things with properties is a dialectical concept, because the tendency is generated by the inherent contradictions that lie within the components that give the thing its properties. It is the contradiction located in the things' components, and not any subsequent events or event patterns that generates the tendency. This is, arguably, the 'inner connection' in and between phenomena that Brown et al (2002) quite correctly see as central to a dialectical analysis. Take, for example, the tendency for an economy to create money. The tendency arises because one commodity (thing) must, but cannot (hence the contradiction) simultaneously take the equivalent and relative form of value. The contradiction is resolved when one commodity negates its form and emerges to take the form of money. The tendency to create money, then, is the (transfactual) way of acting of a thing (commodity) with use and exchange values. ${ }^{23}$

\section{Conclusion: the (genuine) tendency of a company to extract profit}

Once the terms 'tendency', 'law', 'tendential law' and variants are disambiguated, we can look at them in a different way, and see different things. We see that, whilst the five conceptions of law as event regularity/tendency are compatible with the use of mathematics, they are not (genuine) conceptions of tendency at all, but conceptions of 
regularity law in disguise. We see, furthermore, that the (genuine) conception of tendency, namely, tendency as the (transfactual) way of acting of a thing with properties is impossible to mathematise. This means that if Marxist political economists are to investigate (genuine) tendencies, we must develop our traditional qualitative research techniques. I wish to conclude by saying a little more about this. First, I will return to the example of a capitalist company used above and elaborate slightly. Second, I will take the conception of law as event regularity/tendency and consider how we would use quantitative (mathematical and statistical) techniques to investigate the tendential law of a company to extract profit. Third, I will take the conception of law as tendency and consider how we might use qualitative techniques to investigate the tendency of a company to extract profit.

\section{$A$ (very abstract) sketch of a capitalist company}

A capitalist company is a thing with properties, the latter being given by the components that constitute it. Many of these components are, in various ways, and with varying degrees of efficacy, causally implicated in generating (mass and rate of absolute and relative surplus value and hence) profit. The following are some of the most important components - although, at this very high level of abstraction, and I am abstracting from internal factors like productive and unproductive labour and external causal factors such as competition between capitals and macro-economic and macro-political conditions:

- A workforce. A workforce consists of employees and workers whose labour power takes the form of a quasicommodity. Moreover, a workforce is not homogeneous and is often divided by class, gender, race, sexual orientation, nationality, citizenship and so on.

- Working arrangements. There may, for example, be a mixture of permanent employees and temporary workers, not to mention the existence of flexi-time, annualised hours, various shift-patterns etc.

- A management team. A management team owns and/or controls the company. A management team is not homogeneous either and is often divided by status - being a junior manager is very different to being a senior manager or a director who may or may not own and/or control capital. It is almost always divided by gender.

- Mechanisms for managing the workforce. These range from explicit coercion and bullying, via Taylorised forms of technologically-based control, to techniques such as performance management, team-working and performance and profit related pay.

- Mechanisms for hiring, firing, promoting and training. Some of these will be in-house and others outsourced.

- Capital goods such as premises, plant, machinery, equipment, IT systems, raw materials and semi-finished products.

- Mechanisms for receiving revenue and making payments - e.g. payments for capital goods, rent, energy, payment for wages, pensions, tax and national insurance. 
- Mechanisms for financing the company and of corporate governance.

- Industrial relations systems. These may involve actually collective bargaining with union representatives at the plant or company, or acting within such collective systems. It may also involve works councils.

- Mechanisms for negotiating power and conflict. These can range from mechanisms to deal with overt, conscious, collective struggle, individual acts of sabotage and the withdrawal of goodwill, to mechanisms to handle complex negotiations over more subtle, capillary forms of power.

- Mechanisms for generating and inculcating various kinds of ideology, hegemony, discourse and culture.

There are three important points to note here.

First, a company's tendency to extract profit depends not only upon the mere existence of these components, but upon the way they are combined - i.e. content and form. Managers do not simply throw labour and capital ( $L$ and $K$ or $c$ and $v$ ) together in a heap and then wait and see what the outcome is. Indeed many companies employ a barrage of managerial mechanisms (often in the guise of HRM techniques) in an attempt to combine labour and capital optimally, that is, in ways that squeeze as much profit out of labour as possible. Companies that optimally combine all or most of these components have a tendency to generate profit; and companies that do not do this, cannot generate this tendency - or, to say the same thing in a different way, they generate a counter-tendency. And of course, these tendencies and countertendencies are not simply 'on' or 'off', they vary in strength. Orthodox economic theory ignores almost all of this. A company is reduced (in theory only) to a production function where doses of some stuff called 'capital' are (somehow) added to doses of some other stuff called 'labour' and (somehow) some other stuff called 'output' emerges. Many Marxists, on the other hand, do not ignore this. Indeed, Marxists working in disciplines such as industrial relations, human resource management, organisation studies and management studies, and/or in traditions such as Labour Process Theory and Critical Management Theory spend a great deal of their time and effort investigating the way labour and capital are combined.

Second, these components have two dimensions to them: quantitative and qualitative.

i) The quantitative dimension is characterised by things like numbers of workers, wage rates, value and price of capital goods, raw materials, energy, and quantities of outputs and measures of productivity. Focus on the quantitative dimension gives rise to concepts like the organic, technical and value composition of capital, changes in productivity, the magnitudes of absolute and relative surplus value, profit and such like.

ii) The qualitative dimension is characterised not only by obvious qualitative phenomena like culture, discourse and ideology, but also phenomena like working and management practices. These qualitative phenomena 
are every bit as important as quantities of labour and machinery in terms of the tendency to generate profit. Two companies with very similar labour and machinery could generate very different tendencies by having different management techniques for dealing with culture, discourse, ideology, conflict and power. Similarly, the nature of working practices can be every bit as important as the price of capital goods. Two companies paying similar prices for their inputs could generate very different tendencies by having different mixes of workers and different types of flexible working practices - and then, of course, utilising different management techniques on each group. Simply having the most technologically advanced equipment will not necessarily translate into above average profit rates for an individual company if the company cannot, for example, adopt the (business-friendly) flexible working practices of its competitors.

Third, it is from these components, and the relations within and between them, that the 'inner connection' sought by Brown et al (2002) can be found - and the difficulty of this task should not be underestimated. Clearly, I cannot elaborate here upon how we would engage in a process of abstracting the cell form from this chaotic conception, and then presenting the analysis via a hierarchy of categories as a dialectically unfolding presentation. Nevertheless it is not difficult to see that this conception of a tendency as the way of acting of a thing with properties (i.e. properties of the components) lends itself to 'systematic dialectics and systematic abstraction', and need not degenerate into a 'rag-bag approach' (ibid: 783). Indeed, if there is an internal relation between a thing with properties and its tendencies, then this conception of tendency forms a platform from which to identify it and understand its dialectical progression. What it calls into question, however, is the idea that the way in which labour and capital are combined is less abstract (or more concrete) than the fact that labour and capital exists, and/or stand in a ratio to one another, allowing us to put off an analysis of all these other components for a later stage of (lower) abstraction. Put another way, it is questionable whether the organic composition of capital, is ontologically and/or epistemologically prior to the way labour and capital are combined because the combination is as important as the existence of labour and capital in determining the level of surplus value produced. I cannot elaborate further on this matter, and simply note that to the best of my knowledge, no-one has adequately addressed it.

\section{Law event regularity/tendency}

Let us now take the conception of law event regularity/tendency and consider how we would use quantitative (mathematical and statistical) techniques to investigate the tendential law of a company to extract profit. Investigation would start (and finish) with events. It would ascertain the existence (or not) of some of the company's components (e.g. does the company engage in collective bargaining) or measure changes made (e.g. how much highly productive technology has been introduced). These events would then be quantified and transformed into data to become the variables in something like model 4 .

(4) $y=\alpha+X \beta+\varepsilon$ 
The dependent variable (denoted $y$ ) would be some measure of profit. The vector of independent variables (denoted $X$ ) would measure some of the components - including those variables expressing tendential and countertendencies/laws. A judgement would have to be made about which variables should be included in $\boldsymbol{X}$ and which would be abstracted from. Whilst this judgement should be guided by theory, the fact is that anything that cannot be (meaningfully) quantified ${ }^{24}$ cannot be included in $\boldsymbol{X}$. In other words, the focus on the quantifiability of events becomes a necessary, although insufficient, criterion for choosing which variables to include. The model would then be estimated to establish whether or not there is a statistically significant association between $\mathrm{y}$ and $\boldsymbol{X}$. Put another way, the point of the exercise is to establish whether or not there is a (stochastically expressed) regularity between the events expressed in variable $y$ and the events expressed in $\boldsymbol{X}$. If such a regularity can be found, some would claim to have discovered the existence of a tendential law for the company to extract profit.

This kind of investigation would, however, run into the following problems and limitations.

i) Because the conception of law as event regularity/tendency is not a (genuine) conception of tendency but a regularity law in disguise, claiming to have discovered the existence of a tendential law for the company to extract profit is incorrect. The best that could be claimed is to have discovered the existence of a (stochastically specified) regularity law for the company to extract profit. We would not have mathematised a (genuine) tendency, merely a stochastic regularity law.

ii) Regression analysis does not necessitate an in-depth investigation into the way of acting of the various components. All that is necessary is to measure these components along with the event they generate, express them as variables and then analyse the association between them. Whilst this does not exclude such an in-depth investigation, it does not encourage it either. If the variables are found to be statistically significant and correctly signed, then some would claim to have identified a tendential law and, whilst any indepth information about the components (including their 'inner connections') might be nice, it would be unnecessary for the establishment of the tendential law. ${ }^{25}$

iii) Many, if not most, of the components that constitute the company are qualitative and impossible to (meaningfully) quantify. Whilst Marxist political economists almost certainly know this, the moment they opt to mathematise these components, they have no choice but to (do what neoclassical economists do and) ignore all components that cannot be quantified. Attempts to mathematise this tendential law would be partial - at best. 
iv) Suppose that empirical analysis did not establish a statistically significant association between $\boldsymbol{y}$ and $\boldsymbol{X}$. They would have no option but to conclude that there exists no tendential law for the company to extract profit. This would, however, be premature. The transfactual nature of (genuine) tendencies means that (genuine) tendencies can exist without manifesting themselves as events - or variables. The non-existence of events, or event regularities, is not evidence of the lack of a (genuine) tendency in operation.

v) This kind of empirical investigation cannot ascertain the strength of tendencies. In a regression equation the beta coefficients capture the size relationship between dependent and independent variables: as $X$ increases by 1 unit, $Y$ will increase by beta units. If the data are in logs, the beta represents elasticity. But the concept of 'strength of a tendency' is meaningless - even at the level of events. The strength of the tendency for (say) team working to generate profit can, with some difficulty, be understood, but it is difficult to see how it could be measured.

vi) Simply adding more variables to the equation, perhaps to represent more countervailing or offsetting factors generated by the myriad components of the company, does not avoid any of the problems just noted.

In sum, attempts like this to use quantitative (mathematical and statistical) techniques to investigate the tendential law of a company to extract profit, would run into a series of problems and limitations. Most important, however, is the fact that we would not be attempting to mathematise a (genuine) tendency but merely a stochastic regularity law - and not even realising it. And this allows us to see that the mathematisation of a (genuine) conception of tendency is impossible for ontological and aetiological reasons. Law as event regularity/tendency, and mathematics and statistics, both presuppose an atomist and empirical realist ontology of events, an aetiology based on event regularities and closed systems. The (genuine) conception of tendencies, in complete contrast, presupposes a 'layered' ontology that extends beyond the levels of the empirical and the actual, to include the 'deep; an aetiology of causal powers and open systems. ${ }^{26}$

\section{Tendency as the (transfactual) way of acting of a thing with properties}

Let us now take the conception of tendency as the (transfactual) way of acting of a thing with properties and consider how we might go about using qualitative techniques to investigate the tendency of a company to extract profit. The starting point would be to identify the company's (i.e. thing's) components, with the aim of uncovering the ways of acting, and interacting, of the components. This would necessarily entail use of the qualitative research techniques we currently have at our disposal. Whilst the idea of investigating tendencies without quantifying the inputs or the outputs might seem strange, there is no inherent reason why it cannot be done. Indeed, I see no reason why Marxist researchers working in disciplines like the sociology of work, industrial relations, organisation studies and 
management studies could not adapt their qualitative research techniques to investigate tendencies. Let me finish by offering a sketch of how this could be done.

As in the previous case, a judgement would be made about which components should be included and which should be abstracted from - and perhaps also how they should be presented systematically and dialectically. Of each of the components we decide to investigate, we would ask questions like the following: Does this component generate a tendency, or a counter-tendency to extract profit? If so, what are its ways of acting, that is, what exactly does it do and how exactly does it do it? Are its effects intermittent, if so why? Is the tendency strong or weak? And so on. Importantly, because several components are at work simultaneously, we need to analyse their interaction. We need to ascertain whether some component (call it $\mathrm{C}^{1}$ ), with its tendency (call it $\mathrm{T}^{1}$ ) to generate profit, interacts with another component $\left(\mathrm{C}^{2}\right)$ with its counter-tendency $\left(\mathrm{CT}^{2}\right)$ and so on for all components. We also need to ascertain whether the effects of $\mathrm{C}^{1}$ and $\mathrm{C}^{2}$ are intermittent, along with the strength of any tendencies they generate. Let us make the example a little more concrete by imagining a fairly typical research scenario.

Suppose researchers start by investigating the ways of acting of team working $\left(C^{1}\right)$ and (PRP) performance related pay $\left(C^{2}\right)$. Suppose they find that $C^{1}$ generates a weak tendency $\left(T^{1}\right)$ to generate profit, and $C_{2}$ generates a weak tendency to $\mathrm{T}^{2}$. When they investigate the interaction of $\mathrm{C}^{1}$ and $\mathrm{C}^{2}$, however, they find that when PRP interacts with team working, PRP actually generates a counter-tendency. This is because the ethos of individualism encouraged by PRP runs counter to the ethos of collectivism (potentially at least) encouraged by team working. The net result might be a weak composite counter-tendency $\mathrm{CT}^{1+2}$. Suppose, next, that researchers find that the establishment of a Works Council $\left(C^{3}\right)$, combined with the marginalisation of trade unions, by presenting them as outsiders determined to wreck the company $\left(\mathrm{C}^{4}\right)$, interact to create a pro-company ideology (i.e. 'we're all in this crisis together') to create a weak composite tendency to generate profit $\mathrm{T}^{3+4}$. Suppose further that researchers take their findings about the interaction of $C^{1}$, and $C^{2}$ and investigate their (joint) interaction with $C^{3}$ and $C^{4}$ and this reveals a weak composite tendency $T^{1,2,3+4}$. Suppose, finally, that researchers investigate the effect of the joint interaction of $\mathrm{C}^{1}, \mathrm{C}^{2}, \mathrm{C}^{3}$, and $\mathrm{C}^{4}$, and weak composite tendency $\mathrm{T}^{1,2,3+4}$, with the introduction of the most technologically advanced (and thereby potentially highly productive and profitable) machinery available in the industry $\left(\mathrm{C}^{5}\right)$, only to find that all this generates a weak composite counter-tendency $\left(\mathrm{CT}^{5}\right)$ to generate profit. Overall, then, the researcher might conclude that the company does not have a tendency to extract profit.

Before we dismiss this as mere guess-work, bear in mind that capitalists do this all the time, as do trade union negotiators when trying to push the company over pay and conditions - without at the same time bankrupting it. Marxist researchers can do this with far more systematicity, delving into the detail of the practices involved. Researchers can ask workers, managers and other appropriate 'stakeholders' what tensions are created by the interaction, and how they deal with them. Alternatively, researchers may choose to observe (as participants or non- 
participants) tensions created by the interaction, and observe how workers, managers and other 'stakeholders' deal with them. Claims or observations from workers, managers and 'stakeholders' can be checked against each other, giving the research a degree of objectivity - or at least a degree of objectivity no worse than other qualitative research.

This might not be the way Marxist political economists have, hitherto, gone about investigating tendencies, but once the terms 'tendency', 'law', 'tendential law' and variants are disambiguated, the argument for employing qualitative research techniques to investigate (genuine) tendencies becomes difficult to resist.

\section{Author biography}

Steve Fleetwood is a professor at the University of the West of England. He writes on political economy and philosophy of science, especially critical realism. 


\section{References}

Bhaskar, R. (1978) A Realist Theory of Science, Hemel Hempstead: Harvester Wheatsheaf.

Bhaskar, R. (1989) The Possibility of Naturalism, Hemel Hempstead: Harvester Wheatsheaf.

Bhaskar, R. (1993) Dialectic: The Pulse of Freedom, London: Verso.

Bhaskar, R. (1994) Plato Etc. The Problems of Philosophy and Their Resolution, London: Verso.

Bigo, V. (2006) 'Open and Closed Systems in the Cambridge School', Review of Social Economics, Vol. 64, No. 4, 493-513.

Brown, A. Fleetwood, S. Roberts, J. (2002) Critical Realism and Marxism, London: Routledge.

Brown, A. (2007) 'Reorienting Critical Realism: A System-wide Perspective on Capitalist Development', Journal of Economic Methodology, Vol. 14, No. 4, 499-519.

Brown, A. Slater, G. Spencer, D. (2002) 'Driven to Abstracton? Critical Realist and the Search for "Inner Connection" Between Social Phenomena', Cambridge Journal of Economics, No. 226, 773-88.

Cartwright, N. (2007) Hunting Causes and Using Them: Approaches in Philosophy and Economics, Cambridge: Cambridge University Press.

Chick, V. Dow, S. (2005) 'The Meaning of Open Systems', Journal of Economic Methodology, Vol. 12, No. 13, 363-381.

Collier, A. (1994) Critical Realism: An Introduction to Roy Bhaskar's Philosophy, London: Verso.

Cullenberg, S. (1992) 'The Political Economy of Marx's Theory of the Falling Rate of Profit: Methodological Considerations', Methodus, June, 44-54.

Cullenberg, S. (1994) The Falling Rate of Profit: Revisiting the Marxian Debate, London: Pluto.

Cutler, A. et al (1977) Marx's Capital and Capitalism Today: Volume One, London: Routledge \& Keegan Paul.

Dow, S. (2006) 'Themes and Issues: Rejoinder to Steve Fleetwood and to Paul Downward', Journal of Critical Realism, Vol. 5, No. 1, 169-182.

Downward, P. (2003) Applied Economics and the Critical Realist Critique, London: Routledge.

Downward, P. Mearman, A. (2007) 'Retroduction as Mixed-methods Triangulation in Economic Research: Reorienting Economics into Social Science', Cambridge Journal of Economics, No. 31, 77 - 99.

Dúménil, G. Lévy, D. (1993) The Economics of the Profit Rate: Competition, Crises and Historical Tendencies in Capitalism, Cheltenham: Edward Elgar.

Fine, B. Harris, L. (1979)Rereading Capital, London: Macmillan.

Fleetwood, S. (1999) Critical Realism in Economics: Development and Debate, London: Routledge.

Fleetwood, S. (2001a) 'Causal Laws, Functional Relations and Tendencies', Review of Political Economy, Vol. 13, No. 2, 201-220.

Fleetwood, S. (2001b) 'What Kind of Theory is Marx's Labour Theory of Value? A Critical Realist Inquiry', Capital \& Class No. 73, 41-77, reprinted in A. Brown, S. Fleetwood and J. Roberts (2002) Critical Realism and Marxism, London: Routledge. 
Fleetwood, S. (2005) 'A Critical Realist Reply to Walters and Young', Review of Political Economy, Vol. 17, No. 4, $1-14$.

Fleetwood, S. (2006) 'Themes and Issues: Reply to Shelia Dow and Paul Downward,' Journal of Critical Realism, Vol.5, No.1, 158-165 \& 169-182.

Fleetwood, S. (2009) 'The Ontology of Things, Powers and Properties', Journal of Critical Realism, Vol. 8, No. 3, 343-366.

Fleetwood, S. (2011) 'Powers and Tendencies Revisited', Journal of Critical Realism, Vol.10, No. 5, 80-99.

Fleetwood, S. Hesketh, A. (2010) Explaining the Performance of Human Resource Management, Cambridge: Cambridge University Press.

Gibson, Q. (1982) 'Tendencies', Philosophy of Science, No. 50, 296-308.

Harré, R. Maddden, E. (1975) Causal power: A Theory of Natural Necessity, Oxford: Basil Blackwell.

Hamermesh, D. (1993) Labour Demand, Princeton: Princeton University Press.

Hausman, D. (1992) The Inexact and Separate Science of Economics, Cambridge: Cambridge University Press.

Husson, M. (2010) 'The Debate on the Rate of Profit', International Viewpoint, Online magazine, No. 426 July, http://www.internationalviewpoint.org/spip.php?article1894, accessed $7^{\text {th }}$ June 2011.

Johnson, L. Gram, W. Hoas, D. (1991) The Falling Rate of Profit Debate in Marx: Alternative Lines of Interpretation, Cheltenham: Edward Elgar.

Laibman, D. (1993) 'The Falling Rate of Profit: A New Empirical Study', Science and Society, Vol. 57, No. 2, 223-233.

Lawson, T. (1997) Economics and Reality, London: Routledge.

Lawson, T. (2003) Reorienting Economics, London: Routledge.

Lewis, P. (2004). Transforming Economics: Perspectives on the Critical Realist Project, London: Routledge.

Lawson, T. (1994) 'A Realist Theory for Economics', in R. Backhouse, New Directions in Economic Methodology, London: Routledge.

Lawson, T. (1998) 'Tendencies', in Davis, J, Hands, W. Mäki, U. (eds.), The Edward Elgar Companion to Economic Methodology, Cheltenham: Edward Elgar.

MacBride, W. (1977) The Philosophy of Marx, Hutchinson.

Maki, U. (2002) Fact and Fiction in Economics: Models, Realism and Social Construction, Cambridge: Cambridge University Press.

Marx, K, (1984) Capital Vol III, London: Lawrence and Wishart.

Mearman, A. (2006) 'Critical Realism in Economics and Open-Systems Ontology: A Critique', Review of Social

Economy, Vol. LXIV, No. 1, 47-75.

Meikle, S. (1985) Essentialism in the Thought of Karl Marx, Gloucester: Duckworth

Michl, T. (1994) 'Three Models of the Falling Rate of Profit', Review of Radical Political Economics, Vol. 26, No. 4, 5575. 
Mohun, S. Veneziani, R. (2011 forthcoming) 'Reorienting Economics?', Philosophy of the Social Sciences, 1-20.

Moseley, F. (1991) The Falling Rate of Profit in the Post-war United States Economy, London: Macmillan.

Moseley, F. (1997) Marx's Method in Capital: A Re-examination, New Jersey, Humanities Press.

Moseley, F. Campbell, M. (1997) New Investigations of Marx's Method, New Jersey: Humanities Press.

Morgan, M. (2002) 'Models, Stories and the Economic World' in Maki, U. (ed.) Fact and Fiction in Economics: Models, Realism and Social Construction, Cambridge: Cambridge University Press.

Parijs, Van, P. (1995) 'Why Marxist Economics Needs Microfoundations', Marxism Recycled, Cambridge: Cambridge University Press.

Pinkstone, B. Hartwig, M. (2007) 'Tendency', in Hartwig, M. (2007) Dictionary of Critical Realism, London: Routledge.

Pratten, S. 'Realism, Closed Systems and Abstraction', Journal of Economic Methodology, Vol. 14, No. 473-497

Psillos, S. (2002) Causation and Explanation, Chesham: Acumen.

Reuten, G. (1991) 'Accumulation of Capital and the Foundation of the Tendency of the Rate of Profit to Fall', Cambridge Journal of Economics, Vol. 15, 79-93.

Reuten, G (1997) 'The Notion of Tendency in Marx's 1984 Law of Profit', F. Mosely, M. Campbell, New Investigations of Marx's Method, New Jersey, Humanities Press International.

Reuten, G (2004)' "Zirkel vicieux" or Trend Fall? The Course of the Profit Rate in Marx's Capital III', History of Political Economy Vol. 36, No.1, 163-186.

Reuten, G. Williams, M. (1989) Value-Form and the State, London: Routledge.

Roberts, J. (1999) 'Marxism and Critical Realism: The Same, Similar, or Just Plain Different', Capital \& Class, No. 68, $21-49$.

Rosdolsky, R. (1977) The Making of Marx's Capital, Volume I, London: Pluto.

Ruben, D-H. (1979a) Marxism and Materialism: A Study in Marxist Theory of Knowledge, Brighton: Harvester.

Ruben, D-H. (1979b) 'Marxism and Dialectics', in Mepham, J. Ruben, D-H, Issues in Marxist Philosophy Volume One, Brighton: Harvester.

Rubin, I. (1990) Essays on Marx's Theory of Value, Montreal: Black Rose Books.

Sayer, D. (1983) Marx's Method: Ideology, Science and Critique in Capital, Brighton: Harvester.

Tsaliki, P. Tsoulfidis, L. (1994) 'Profitability and Accumulation in Greek Manufacturing', International Review of Applied Economics, Vol. 81, №. 1, 26-62.

Zelený, J. (1980) The Logic of Marx, Oxford: Basil Blackwell.

\footnotetext{
1 I wish to thank Geert Reuten, Andrew Brown, Heikki Patomaki, Paul Lewis, Jamie Morgan, Brian Pinkstone and Steve Pratten for their insightful comments on earlier drafts of this paper. Special thanks go to Andrew Kliman who, whilst disagreeing, helped me clarify some difficult arguments.

2 Ideas of tendency and tendential law are to be found in Carchedi (1993); Fine \& Harris (1979); MacBride (1977); Meikle (1985); Ollman (1993); Reuten \& Williams (1989); Ruben (1979a\&b); Sayer (1983); Wilson (1991) and Zeleny
} 
(1980). Despite entitling a chapter 'Epistemology, causality and the laws of tendency', there is very little on the concept of tendency in Cutler et al (1977); part II, especially chapter 4. Moseley's (1991) book on the falling rate of profit uses the term 'law of the tendency', but carries no discussion of these terms and there is no entry for 'tendency' in the index. The same goes for Dumenil \& Levy's (1993) book on the economics of the profit rate. Cullenberg's (1992) paper on the falling rate of profit subtitled 'methodological considerations' does not tackle methodological issue vis-à-vis laws and tendencies either - although it is touched upon in his (1994) book. The most recent article I could find on tendencies (in this case of the rate of profit to fall) by Husson (2010) does not define the term 'tendency' either.

${ }^{3}$ I thank Andrew Kliman for this observation, although it is only fair to point out that he does not think this is ambiguous: for Andrew, the fall, not the law, is tendential.

${ }^{4}$ Bhaskar's work on laws and tendencies is found primarily in Bhaskar (1978), and secondarily in (1989), (1993) and (1994). Fleetwood (2010 \& 2011) has written specifically on powers and tendencies. Overviews of critical realist ideas in economics can be found in Downward (2003); Fleetwood (1999); Lawson (1995 \& 2003); and Lewis (2004). For critical realism and Marxism see Brown, Fleetwood \& Roberts (2002). Other philosophers of economics such as Hausman (1992) mention laws and tendencies, but in his case, largely via the work of J.S. Mill. Cartwright (2007) deals explicitly with laws and, to a lesser extent, tendencies. It is not clear whether her concept of tendency, which also appears to derive from J.S. Mill, is similar to the one I am trying to develop. Incidentally, I do not re-visit Mill in order to disambiguate the term 'tendency' for the same reasons I do not revisit Marx.

${ }^{5}$ Reuten (1997) is an exception in the last two cases.

${ }^{6}$ See also Bhaskar (1978); Fleetwood (2001a \& 2005); Lawson (1997) and Psillos (2002).

7 Tendency as trend and cycle are often combined when we have a cyclical fluctution around a trend.

${ }^{8}$ Note that tendency as trend and as cyclical variation are also expressed stochastically, with the independent variable being time.

${ }^{9}$ See Cartwright (2007, chapter 12) for a detailed discussion of causality and probability.

${ }^{10}$ See Morgan, (2002) for an elaboration.

${ }^{11}$ On $p$ ? I will return to this point to show the crux of the distinction between counterfactuals and transfactuals.

12 The debate within economics about the nature and legitimacy of mathematical modelling rumbles on - see, for example, the collection edited by Maki (2002). Writing specifically about laws and tendencies, Cartwright (2007, chapter 15) offers a detailed discussion of what she calls 'analogue economies' - i.e. typical mathematical models of economies. Whilst she is not entirely clear, she does suggest that these models can 'teach us about general tendencies that are nakedly displayed in the analogue economies described in our economic models but that stand ready to operate in most economies' (2007: 231). At the same time, however, she doubts that these models can be applied outside of the study. For recent comments see Mohun \& Veneziani (2011).

${ }^{13}$ Lawson (1997) does not, however, link stylised facts and demi-regularities with tendencies, nor does he use tendency in this imprecise or under-elaborated way.

${ }^{14}$ Carchedi (1993: 193) refers to this as the 'future tendency, which is found by forecasting the future tendential reality on the basis of the present movement'. Whilst I admire Carchedi's attempts to unpack the concept of tendencies, I find his three types of (present) tendencies confused and confusing. I think this is, in part, due to his (arguably incorrect) starting point. A tendency, he correctly points out 'manifests itself through the real movement of specific events'. He then adds that 'different types of tendencies can be discerned by analysing the real movement' (ibid: 194). If I am right, and tendencies are not associated with events, but are powers that govern the flux of events, then differences in types of tendencies cannot be sought at the level of events. Carchedi flirts with empirical conceptions of tendencies, whilst at the same time trying to deny he is doing this. 
${ }^{15}$ Notice that this is an example of interpretation ( $v$ ) above, tendency as a deliberately imprecise and underelaborated concept.

${ }^{16}$ It is not the case that the natural world is characterised by regularity law and the social world characterised by laws as event regularity/tendency, or (genuine) tendency. For critical realists all laws are tendencies, even in natural science. The reason things like Ohm's Law are often (mis)understood as regularity laws is because the systems in which they normally operate are, or approximate closely to, closed systems. To be strictly accurate, even Ohm's Law does not manifest itself in perfect event regularities - but this only strengthens the case for the ubiquity of open systems.

${ }^{17}$ Event regularities and open and closed systems are a central part of critical realist meta-theory - although there is some debate over the concept. See Brown (2007); Bigo (2006); Chick \& Dow (2005); Dow (2006); Downward (2006); Downward \& Mearman (2007); Fleetwood (2001a, 2001b and 2006); Lawson (1997) and (2003).

18 I apologise in advance to David Laibman. I am not suggesting that he would try to do such a thing, I simply needed an equation to illustrate a point and his paper has the advantage of being exceptionally clear.

${ }^{19}$ Some may see a family resemblance here between the (nonsensical) concept of 'tending to equal' and the concept of an asymptote - i.e. a line that a graph gets closer and closer to (as we go to infinity) but never intersects. It is difficult to say if there is a resemblance because, unlike the concept of an asymptote, the concept of 'tending to equal' has no real meaning; indeed I am using it hypothetically. I am not, however, aware of anyone who has tried to treat the tendency of the rate of profit to fall in asymptotic terms. Moreover, as we will see in part three, my real argument is against all conceptions that treat a tendency as an outcome, as the magnitude of a dependent variable.

20 Lawson (1998) refers to a 'tendency as an enduring orientation'. It is compatible with the conception I develop here.

${ }^{21}$ This should not be understood as vulgar materialism. An entity can have tendencies that are ascribed to it by the community that have little or nothing to do with its material constitution - I am thinking here of religious symbolism, or indeed many forms of fetishism. The point remains, a tendency like this is social (not material) and is still created at the moment when the entity is created - e.g. a taboo. On the difference between materially, socially, artefactually and conceptually real entities, see Fleetwood (2005).

${ }^{22}$ This does not, of course, mean that the thing that generated the event/variable cannot change its nature or become something else, but we are not dealing with this thing when we are dealing with events.

${ }^{23}$ Whilst it would be extremely useful, at this point, to 'dialecticise' this (critical realist) interpretation of tendency by linking it to New Dialectics, unfortunately, to do it properly would require another paper. Roberts (1999) and Brown (2007) have made a start on this.

${ }^{24}$ Almost anything can be quantified with enough assumptions, but the question is: would the quantity be plausible, sensible, or meaningful. On meaningful quantification see Fleetwood \& Hesketh (2010, chapter 4).

25 Incidentally, I cannot see how a regression equation can be presented dialectically. The best we could do is start with a relation between two variables, deemed to be most abstract, then add a third, slightly less abstract variable, then a fourth and so on. But this is simply mechanical addition and has nothing to do with dialectics.

${ }^{26} \mathrm{It}$ might be useful to have another look at diagram 3 . 